\title{
Indications and complications of androgen deprivation therapy
}

Fankhauser, Christian Daniel ; Wettstein, Marian Severin ; Reinhardt, Michèle ; Gessendorfer, Axel ; Mostafid, Hugh ; Hermanns, Thomas

\begin{abstract}
OBJECTIVE: To review the indications for and side effects of androgen deprivation therapy (ADT) in men affected by prostate cancer. DATA SOURCES: National guidelines, evidence-based summaries, peer-reviewed studies, and websites. CONCLUSION: Indications for ADT include men with (1) intermediate- to high-risk localised prostate cancer undergoing radiation therapy, (2) biochemical recurrence after radical prostatectomy treated with salvage radiation therapy, or (3) metastatic prostate cancer. Several forms of ADT are available. To support self-management, body weight, diet, physical activity, alcohol consumption, and smoking should be discussed during clinical consultations. Important side effects of ADT may include flare-up phenomena of $\mathrm{GnRH}$ analogues, local reactions at injection sites, cardiovascular events, bone loss/fractures, drug-drug interactions, urinary tract dysfunction, hot flashes, cognitive impairment, seizure falls, and liver impairment. IMPLICATIONS FOR NURSING PRACTICE: Nurses have a role in personalized cancer care and should be familiar with indications, side effects, and interventions to optimize quality of life for men affected by prostate cancer receiving ADT.
\end{abstract}

DOI: https://doi.org/10.1016/j.soncn.2020.151042

Posted at the Zurich Open Repository and Archive, University of Zurich

ZORA URL: https://doi.org/10.5167/uzh-191324

Journal Article

Accepted Version

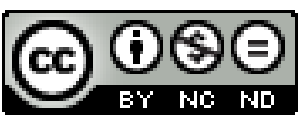

The following work is licensed under a Creative Commons: Attribution-NonCommercial-NoDerivatives 4.0 International (CC BY-NC-ND 4.0) License.

Originally published at:

Fankhauser, Christian Daniel; Wettstein, Marian Severin; Reinhardt, Michèle; Gessendorfer, Axel; Mostafid, Hugh; Hermanns, Thomas (2020). Indications and complications of androgen deprivation therapy. Seminars in Oncology Nursing, 36(4):151042.

DOI: https://doi.org/10.1016/j.soncn.2020.151042 


\section{Indications and complications of androgen deprivation therapy}

Christian Daniel Fankhauser 1, Marian Severin Wettstein'1, Michèle Reinhardt 1, Axel Gessendorfer $^{2}$, Reinhardt ${ }^{1}$, Hugh Mostafid ${ }^{3 *}$, Thomas Hermanns ${ }^{1}$

${ }^{1}$ Department of Urology, University Hospital, University of Zurich, Zurich, Switzerland

${ }^{2}$ XUND Bildungszentrum Gesundheit Zentralschweiz, Luzern, Switzerland

${ }^{3}$ Department of Urology, Department of Urology, Royal Surrey Hospital, Egerton Road, Guildford, Surrey, UK

*Corresponding Author: Hugh Mostafid, Department of Urology, Royal Surrey Hospital, Egerton Road, Guildford, Surrey, UK, GU2 7XX, Hugh.Mostafid@nhs.net

\section{Abstract}

\section{Objective}

To review the indication and side effects of androgen deprivation therapy (ADT) in men affected by prostate cancer.

\section{Data Sources}

National guidelines, evidence-based summaries, peer-reviewed studies, and websites.

\section{Conclusion}

Indications for ADT include men with (1) intermediate to high-risk localised prostate cancer undergoing radiation therapy, (2) biochemical recurrence after radical prostatectomy treated with salvage radiation therapy or (3) metastatic prostate cancer. Several forms of ADT are available. To support self-management body weight, diet, physical activity, alcohol consumption and smoking should be discussed during clinical consultations. Important sideeffects of ADT may include flare-up phenomena of $\mathrm{GnRH}$ analogues, local reactions at 
injection sites, cardiovascular events, bone-loss/fractures, drug-drug interactions, urinary tract dysfunction, hot flashes, cognitive impairment, seizure falls and liver impairment.

\section{Implications for Nursing Practice}

Nurses have a role in personalized cancer care and they should be familiar with indications, side effects and interventions to optimize quality of life for men affected by prostate cancer receiving ADT.

Keywords: Prostate cancer, Androgen deprivation therapy, Nursing, Side effects

\section{INDICATIONS FOR ANDROGEN DEPRIVATION THERAPY}

Prostate cancer $(\mathrm{PCa})$ represents one of the most common neoplasms among men with almost $1^{\prime} 300^{\prime} 000$ new cases and 360 ' 000 deaths in $2018^{1}$ accounting for $15 \%$ of all cancers diagnosed. Prostate cancer is the fifth leading cause of cancer death in men and represents $7 \%$ of total cancer mortality in men $^{2}$. The disease is driven by androgen steroid hormones, which activate the androgen receptor (AR) transcription factor ${ }^{3}$. Given this dependency on testosterone in order to grow, the function of the AR receptor represents the main therapeutic target approached by several different strategies and summarized by the umbrella term androgen deprivation therapy (ADT). Currently available forms of ADT include bilateral orchiectomy, Gonadotropin-releasing hormone $(\mathrm{GnRH})$ analogues or antagonists and anti-androgens. The indications for ADT mainly include men with (1) intermediate to high-risk localised prostate cancer undergoing radiation therapy, (2) biochemical recurrence after radical prostatectomy treated with salvage radiation therapy or (3) metastatic prostate cancer.

Although there are many ways to target the AR, several clinical studies shed light which ADT should be initiated in which group of patients. Generally speaking there is no clear evidence in favor of orchiectomy, GnRH analogue or antagonist. However, in the specific case of patients 
with impending spinal cord compression guidelines recommend either orchidectomy or GnRH antagonists over GnRH analogues because GnRH antagonists don't have the flare-up phenomena. In contrast, anti-androgens alone are only recommended in men with biochemical recurrence treated with salvage radiation therapy.

Because disease specific recommendations do not exist, logistic and economic considerations may help to choose a certain ADT. For patients without access to medical care on a regular base, orchiectomy may represent an ideal option. Whereas men refraining from a mutilating surgery with negative psychological consequences may be offered $\mathrm{GnRH}$ analogue or antagonist. As indicated in Table 1, GnRH analogue implants have the advantage of easier application and are the preferred option from a caregiver ${ }^{4}$ and economic ${ }^{5}$ perspective, particularly if administered at 6 monthly applications ${ }^{6}$.

Despite ADT agents leading to response in nearly all metastatic prostate cancer patients, almost all patients will progress to castration resistant prostate cancer (CRPC), meaning that their cancer is growing despite castrate levels of testosterone. Advances in our understanding of the biology and progression mechanisms to CRPC has informed the development of next generation ADT drugs. Next generation ADT include abiraterone acetate (Zytiga $\left.{ }^{\circledR}\right)$, enzalutamide (Xtandi $\left.{ }^{\circledR}\right)$, apalutamide $\left(\right.$ Erleada $\left.{ }^{\circledR}\right)$ and darolutamide $\left(\right.$ Nubeqa $\left.{ }^{\circledR}\right)$ but can cost $>50,000 \$$ per patients per year and some specific caveats must be kept in mind. Given the high prevalence of men requiring ADT together with an increasing complexity of the disease, nurses can optimize supportive care for men receiving ADT ${ }^{7}$ and have the responsibility of administration and monitoring response to therapy and side-effect, while being safely embedding in the multidisciplinary team ${ }^{7}$. 


\section{SIDE EFFECTS OF ANDROGEN DEPRIVATION THERAPY}

Many men on ADT will grapple with side effects which can negatively affect physical and psychological outcomes, of both the man and his partner/spouse. Therefore, providing patient education and awareness to optimize supported self-management strategies may improve quality of life and the couples adjustment. Several side effects of ADT can at least partially be prevented or ameliorated by following a healthy $\operatorname{diet}^{8}$, maintaining a normal weight, engaging in physical activity ${ }^{9-11} 12$, limiting alcohol consumption and smoking cessation. At each clinical consultation life-style modifications should be discussed, supported and encouraged by the healthcare professional to provide tailored self-management advice to meet the individual patients needs and preferences. In particular dietary instruction is also of importance regarding the timing of drug administration for example, abiraterone should be taken during fasting conditions. The following side effects are of clinical significance and are discussed in detail below.

\section{Flare up}

A unique consequence of GnRH analogues is the testosterone "flare-up" phenomenon which can be experienced for several days after the first injections and may lead to increased bone pain, acute bladder outlet obstruction, obstructive renal failure, spinal cord compression, and cardiovascular death ${ }^{13}$. Therefore, to protect patients from experiencing the testosterone flare following the administration of $\mathrm{GnRH}$, patients are also given a first-generation anti-androgen during the first 2-4 weeks after initiation of GnRH analogues ${ }^{13}$.

\section{Local complications of ADT injections}

As outlined in Table 1 different GnRH analogues or antagonists are available. Although postinjection bruising has been reported more frequently with the implant compared with a reconstituted formulation, there were no observed differences in pain levels or the requirement 
for analgesia in men receiving different administration of ADT agents ${ }^{4}$. Nurses should take care and caution while injecting the implant into the anterior abdominal wall due to the proximity of underlying inferior epigastric vessels and its branches. In case of painful injections or hematoma nurses must monitor patients according to the local reaction observed. Patients with anticoagulation or cachexia should be given a reconstituted formulation instead of an implant. Moreover, the reconstituted formulation should be administered slowly and the needle should not retracted too fast because this may lead to a local reaction if the skin comes into contact with the ADT formulation. Some of those local administration site reactions may be misinterpreted as an abscess in clinical practice which may result in unnecessary surgical removal for the patient.

\section{Cardiovascular complications}

After initiation of ADT men are likely to experience body weight gain, reduced insulin sensitivity and dyslipidemia ${ }^{14}$ therefore significantly increasing their risk for cardiovascular complications ${ }^{15}$. We recommend a cardiology consultation for men with a history of cardiovascular disease, and for men older than 65 years prior to starting ADT $^{13}$. Furthermore, life-style modifications, close monitoring of blood pressure, lipid profile, and blood glucose levels is recommended ${ }^{15,16}$.

\section{Bone loss and fractures}

It has been observed that men receiving ADT show an increased bone turnover and decreased bone mineral density therefore increasing the risk of fractures. To reduce the risk of fractures life-style modifications, monitoring serum levels of vitamin D and calcium and early supplementation is recommended ${ }^{13}$. A personalized fracture risk assessment using the WHO FRAX tool (http://www.shef.ac.uk/FRAX) can be used in practice to decide whether a bone protective agent such as bisphosphonates or denosumab should be prescribed. Denosumab use is associated with an increased risk of osteonecrosis of the jaw and therefore, consultation with 
a dentist before starting of denosumab is strongly recommended. After initiation of ADT regular screening for risk factors to prevent fractures is advised using dual energy radiographic absorptiometry (DEXA) ${ }^{16}$.

\section{Drug-drug interactions}

Men affected by prostate cancer represents an aging population with high co-medication use for multiple comorbidities and increased risk of drug-drug interactions. Next-generation ADT agents differ regarding their drug-drug-interactions and these can be observed in up to $85 \%$ of men, which include medications such as opiates, proton-pump inhibitors, statins, alphablockers, anti-cholinergics and nifedipine ${ }^{17,18}$. Because such drug-drug interactions can have fatal complications we strongly advise to always assess co-medication and perform a new drug interaction test before choosing next-generation ADT agents.

\section{Urinary tract function}

Although ADT does decrease International Prostate Symptom Score (IPSS)patient selfreported scores, prostate volume ${ }^{19}$ and increases urinary flow ${ }^{20}$, men on ADT compared to healthy controls have a higher risk of experiencing lower urinary symptoms (LUTS) ${ }^{21,22}$. Around $15 \%$ of men may require urethral dilatation and/or transurethral resection of the prostate (TURP) within 5 years of receiving ADT ${ }^{23} 24$. To improve LUTS, alpha blockers ${ }^{25}$ as well as choosing GnRH antagonists instead of GnRH analogues have been suggested in a recent study ${ }^{26}$. Additionally, it should be kept in mind that the drug-drug-interaction of enzalutamide might minimize the efficacy of alpha-blockers and anti-cholinergics and therefore alternative options of next-generation ADT drugs should be considered. Progression of symptoms and the need for TURP is a worse predictor of cancer progression ${ }^{27}$ but TURP can safely be offered and successfully improves local symptoms in $80 \%{ }^{28}$. Additionally, bilateral orchiectomy can be performed under the same anesthesia. Men on ADT have an increased risk of $20-30 \%{ }^{29} 14$ of developing acute kidney injury within the first year on ADT 
which is 2.5 higher odds compared to the matched controls ${ }^{30}$. Urinary tract complications are frequent in men receiving ADT and therefore the benefit of regular assessment which should include urine flow, post void residual volume, renal sonography and creatinine assessment should be considered.

\section{Loss of energy and strength}

Loss of energy is often referred to as asthenia or fatigue and a common side effect in men undergoing ADT. Beside above-mentioned life-style modifications, screening for underlying diseases including anemia and hypothyroidism may offer therapeutic options to improve this debilitating side-effect in men Similarly muscle loss is a common symptom ${ }^{31}$ and therefore, referring patients to an exercise physiologist and dietitian can be helpful to improve energy levels, strength, physical conditioning, and mood in men receiving ADT.

\section{Hot flushes}

Hot flushes affect up to $75 \%$ of men treated with ADT but there are limited therapeutic options to alleviate this side-effect. There are several agents such as clonidine ${ }^{32}$ and gabapentin ${ }^{33}$ which has demonstrated a limited efficacy in controlling hot flushes. Whereas, other agents which include estrogen ${ }^{34}$ or progestational ${ }^{35}$ have displayed a significant reduction in hot flushes but were associated with further side-effects. Despite limited evidence on the efficacy of such agents in controlling hot flushes, current clinical guidelines recommend prescribing a selective serotonin or noradrenergic reuptake inhibitors ${ }^{16}$. More recently, anti-cholinergics have been discussed as potential treatment options for hot flushes in prostate cancer patients ${ }^{36}$ as a clear efficacy has been shown in postmenopausal women ${ }^{37}$ and breast cancer survivors who were receiving tamoxifen or aromatase inhibitors ${ }^{38}$. However, further research is needed to test the mechanism effect of anti-cholinergic in men. 


\section{Sexual function and genital changes}

A decrease in libido and erectile dysfunction is experienced in most patients on ADT, which can result in changes in the couple's relationship. A multidisciplinary ADT Survivorship Working Group suggested to prepare the couple for changes in sexual function and discuss couple centered goals and expectation before administering ADT. Sexual well-being interventions can be offered and discussed such as, phosphodiesterase 5 inhibitors, vacuum therapy to promote quality erections, transdermal estradiol for desire, and sexual therapy/mindfulness techniques ${ }^{39}$. Noteworthy, the influence of estradiol on oncological and cardiovascular outcomes is unclear and should only be recommended with caution.

To ensure individualized couple preferences and needs are met, intervene early and discuss realistic expectation by promoting flexibility and talk in an open and nonjudgmental manner. Moreover, healthcare professionals should encourage intimacy despite low libido such as physical affection such as holding hands, hugging, physical touch, kissing, and cuddling to prevention erosion in spousal bond.

Increase in breast size or tenderness occurs in $90 \%$ of men with anti-androgens and $30 \%$ on GnRH analogue or antagonist and genital shrinkage including penile length and testicular size occurs in $>90 \%{ }^{40}$. Either radiotherapy of the breasts ${ }^{41}$ or daily tamoxifen $(20 \mathrm{mg})$ could prevent gynecomastia $^{41,42}$ and mastectomy or liposuction could be used to manage existing breast enlargement ${ }^{39}$. Provide psychological support as men can experience feelings of embarrassment related to gynecomastia, review analgesia for pain/discomfort, and suggest the use of camouflage in clothing item selection. 


\section{Neuropsychiatric side-effects}

Several retrospective studies suggested an association between ADT with cognitive impairment ${ }^{43}$, Alzheimer's disease ${ }^{44}$, depression ${ }^{45}$, suicide and falls ${ }^{46}$. As shown in localised prostate cancer patients group-based cognitive-behavioral stress management could improve quality of life ${ }^{47} 48$ whereas there are no definite recommendations to prevent or treat cognitive impairment. The additional negative impact of next-generation ADT needs to be clarified, specifically as they differ substantially regarding blood brain barrier penetration ${ }^{49}$.

\section{Liver function}

Prostate cancer patients on ADT compared to men not on ADT may have an increased risk for liver diseases ${ }^{50}$. Because hepatic impairment decreases the elimination of abiraterone, men treated with abiraterone are at risk for liver dysfunction and abiraterone is contraindicated in men with severe hepatic impairment ${ }^{18,51}$.

\section{Nursing Implications}

Beside the manys side-effects discussed above, it has to be expected that many other medical or social issues may arise during ADT for the man and his partner/spouse. 
Each consultation with a patient and his partner/spouse is exceptionally unique and provides the healthcare professional with a very privileged glimpse into a person's life and concerns at that moment. A nurse consultation provides an opportunity to explore the patient's problems and identify areas of most concern to tailor intervention at the individual level of need which will invariably change over the cancer care continuum. Therefore, we would recommend regular screening by structured interviews, or patient reported outcome measures such as Holistic Needs Assessments (HNA) to identify areas of concern. Implementing paper and pen HNA in routine clinical practice means that men do not have to verbalise embarrassing concerns aloud, but instead the nurse can tactfully focus the consultation to the areas of most concern to the man and partner/spouse as identified in the HNA to ensure personalised and optimal care.CONCLUSION Nurses are a valuable contact for patients and their families and provide care co-ordination across the multidisciplinary team for men affected by prostate care receiving ADT. Nurses must be educated in the indications and side-effects of androgen deprivation therapy. Moreover, nurse should provide evidence-based interventions to alleviate side-effects, signpost patients for supportive care services in the community, and refer patients as appropriate to the MDT team. Given the complexity of prostate cancer therapies arising from ADT side effects nurses are the hub of cancer care to educate patients and families about expected side-effects of ADT, offered supported self-management to ultimately improve quality of life, costs and compliance of patients.

\section{Acknowledgements}

None. 
None.

\section{Conflicts of interest}

There are no conflicts of interests.

\section{REFERENCES}

1. Bray F, Ferlay J, Soerjomataram I, Siegel RL, Torre LA, Jemal A. Global cancer statistics 2018: GLOBOCAN estimates of incidence and mortality worldwide for 36 cancers in 185 countries. CA: A Cancer Journal for Clinicians. 2018;68(6):394-424.

2. Ferlay J, Soerjomataram I, Dikshit R, et al. Cancer incidence and mortality worldwide: sources, methods and major patterns in GLOBOCAN 2012. International journal of cancer. 2015;136(5):E359-386.

3. Scher HI, Sawyers CL. Biology of progressive, castration-resistant prostate cancer: directed therapies targeting the androgen-receptor signaling axis. Journal of clinical oncology : official journal of the American Society of Clinical Oncology. 2005;23(32):8253-8261.

4. Montgomery BS, Borwell JP, Higgins DM. Does needle size matter? Patient experience of luteinising hormone-releasing hormone analogue injection. Prostate cancer and prostatic diseases. 2005;8(1):66-68.

5. Erdkamp F, Boone N, Janknegt R, Zambon V. GnRH agonists and antagonists in prostate cancer. Generics and Biosimilars Initiative Journal. 2014;3.

6. Wex J, Sidhu M, Odeyemi I, Abou-Setta AM, Retsa P, Tombal B. Leuprolide acetate 1-, 3-and 6monthly depot formulations in androgen deprivation therapy for prostate cancer in nine European countries: evidence review and economic evaluation. ClinicoEconomics and outcomes research: CEOR. 2013;5:257.

7. Lebret T, Bouregba A. Roles of the urologist and nurse from the perspective of patients with prostate cancer receiving luteinizing hormone-releasing hormone analogue therapy. BJU international. 2008;102(10):1419-1424.

8. Turner L, Poole K, Faithfull S, Griffin BA. Current and future strategies for the nutritional management of cardiometabolic complications of androgen deprivation therapy for prostate cancer. Nutrition research reviews. 2017;30(2):220-232.

9. Galvao DA, Taaffe DR, Spry N, Joseph D, Newton RU. Combined resistance and aerobic exercise program reverses muscle loss in men undergoing androgen suppression therapy for prostate cancer without bone metastases: a randomized controlled trial. Journal of clinical oncology. 2010;28(2):340-347.

10. Culos-Reed SN, Robinson JW, Lau $\mathrm{H}$, et al. Physical activity for men receiving androgen deprivation therapy for prostate cancer: benefits from a 16-week intervention. Supportive Care in Cancer. 2010;18(5):591-599.

11. Nilsen TS, Raastad T, Skovlund E, et al. Effects of strength training on body composition, physical functioning, and quality of life in prostate cancer patients during androgen deprivation therapy. Acta Oncologica. 2015;54(10):1805-1813.

12. Taaffe DR, Buffart LM, Newton RU, et al. Time on androgen deprivation therapy and adaptations to exercise: secondary analysis from a 12-month randomized controlled trial in men with prostate cancer. BJU international. 2018;121(2):194-202. 
13. Cornford P, Bellmunt J, Bolla M, et al. EAU-ESTRO-SIOG Guidelines on Prostate Cancer. Part II: Treatment of Relapsing, Metastatic, and Castration-Resistant Prostate Cancer. European urology. 2017;71(4):630-642.

14. Hershman DL, Unger JM, Wright JD, et al. Adverse Health Events Following Intermittent and Continuous Androgen Deprivation in Patients With Metastatic Prostate Cancer. JAMA Oncology. 2016;2(4):453-461.

15. Levine GN, D'Amico AV, Berger P, et al. Androgen-deprivation therapy in prostate cancer and cardiovascular risk: a science advisory from the American Heart Association, American Cancer Society, and American Urological Association: endorsed by the American Society for Radiation Oncology. Circulation. 2010;121(6):833-840.

16. Resnick MJ, Lacchetti C, Bergman J, et al. Prostate cancer survivorship care guideline: American Society of Clinical Oncology Clinical Practice Guideline endorsement. Journal of clinical oncology : official journal of the American Society of Clinical Oncology. 2015;33(9):1078-1085.

17. Benoist GE, van Oort IM, Smeenk S, et al. Drug-drug interaction potential in men treated with enzalutamide: Mind the gap. British Journal of Clinical Pharmacology. 2018;84(1):122-129.

18. Benoist GE, Hendriks RJ, Mulders PF, et al. Pharmacokinetic aspects of the two novel oral drugs used for metastatic castration-resistant prostate cancer: abiraterone acetate and enzalutamide. Clinical pharmacokinetics. 2016;55(11):1369-1380.

19. Axcrona $\mathrm{K}$, Aaltomaa S, da Silva CM, et al. Androgen deprivation therapy for volume reduction, lower urinary tract symptom relief and quality of life improvement in patients with prostate cancer: degarelix vs goserelin plus bicalutamide. BJU international. 2012;110(11):1721-1728.

20. Choi H, Chung H, Park JY, Lee JG, Bae JH. The Influence of Androgen Deprivation Therapy on Prostate Size and Voiding Symptoms in Prostate Cancer Patients in Korea. International neurourology journal. 2016;20(4):342-348.

21. Carlsson S, Drevin L, Loeb S, et al. Population-based study of long-term functional outcomes after prostate cancer treatment. BJU international. 2016;117(6b):E36-45.

22. Kopp RP, Marshall LM, Wang PY, Bauer DC, Barrett-Connor E, Parsons JK. The burden of urinary incontinence and urinary bother among elderly prostate cancer survivors. European urology. 2013;64(4):672-679.

23. Berge $\mathrm{V}$, Thompson T, Blackman D. Additional surgical intervention after radical prostatectomy, radiation therapy, androgen-deprivation therapy, or watchful waiting. European urology. 2007;52(4):1036-1043.

24. Trial IvdtfapcirotMRC. The Medical Research Council Prostate Cancer Working Party Investigators Group. Br J Urol. 1997;79:235-246.

25. Zhang T, Wu H, Liu S, He W, Ding K. Clinical evaluation of tamsulosin in the relief of lower urinary tract symptoms in advanced prostate cancer patients. International urology and nephrology. 2017;49(7):1111-1117.

26. Choi SY, Ryu J, You D, et al. Oncological effect of palliative transurethral resection of the prostate in patients with advanced prostate cancer: a propensity score matching study. Journal of cancer research and clinical oncology. 2018;144(4):751-758.

27. Krupski TL, Stukenborg GJ, Moon K, Theodorescu D. The relationship of palliative transurethral resection of the prostate with disease progression in patients with prostate cancer. BJU international. 2010;106(10):1477-1483.

28. Michielsen DP, Coomans D, Engels B, Braeckman JG. Bipolar versus monopolar technique for palliative transurethral prostate resection. Archives of medical science : AMS. 2010;6(5):780786.

29. Gandaglia G, Sun M, Hu JC, et al. Gonadotropin-releasing hormone agonists and acute kidney injury in patients with prostate cancer. European urology. 2014;66(6):1125-1132.

30. Lapi F, Azoulay L, Niazi MT, Yin H, Benayoun S, Suissa S. Androgen Deprivation Therapy and Risk of Acute Kidney Injury in Patients With Prostate Cancer. JAMA. 2013;310(3):289-296.

31. Lam T, McLean M, Hayden A, et al. A potent liver-mediated mechanism for loss of muscle mass during androgen deprivation therapy. Endocrine connections. 2019;8(5):605-615.

32. Loprinzi CL, Goldberg RM, O'Fallon JR, et al. Transdermal clonidine for ameliorating postorchiectomy hot flashes. The Journal of urology. 1994;151(3):634-636. 
33. Loprinzi CL, Dueck AC, Khoyratty BS, et al. A phase III randomized, double-blind, placebocontrolled trial of gabapentin in the management of hot flashes in men (NOOCB). Annals of oncology : official journal of the European Society for Medical Oncology. 2009;20(3):542-549.

34. Atala A, Amin M, Harty Jl. Diethylstilbestrol in treatment of postorchiectomy vasomotor symptoms and its relationship with serum follicle-stimulating hormone, luteinizing hormone, and testosterone. Urology. 1992;39(2):108-110.

35. Loprinzi CL, Michalak JC, Quella SK, et al. Megestrol acetate for the prevention of hot flashes. N Engl J Med. 1994;331(6):347-352.

36. Smith TJ, Loprinzi CL, Deville C. Oxybutynin for Hot Flashes Due to Androgen Deprivation in Men. New England Journal of Medicine. 2018;378(18):1745-1746.

37. Simon JA, Gaines T, LaGuardia KD. Extended-release oxybutynin therapy for vasomotor symptoms in women: a randomized clinical trial. Menopause (New York, NY). 2016;23(11):1214-1221.

38. Leon-Ferre R, Novotny P, Faubion S, et al. A randomized, double-blind, placebo-controlled trial of oxybunin (Oxy) for hot flashes (HF): ACCRU study SC-1603. Paper presented at: Proceedings of the San Antonio Breast Cancer Symposium2018.

39. Elliott S, Latini DM, Walker LM, Wassersug R, Robinson JW. Androgen deprivation therapy for prostate cancer: recommendations to improve patient and partner quality of life. The journal of sexual medicine. 2010;7(9):2996-3010.

40. Walker LM, Tran S, Robinson JW. Luteinizing hormone-releasing hormone agonists: a quick reference for prevalence rates of potential adverse effects. Clinical genitourinary cancer. 2013;11(4):375-384.

41. Perdona S, Autorino R, De Placido S, et al. Efficacy of tamoxifen and radiotherapy for prevention and treatment of gynaecomastia and breast pain caused by bicalutamide in prostate cancer: a randomised controlled trial. The Lancet Oncology. 2005;6(5):295-300.

42. Fradet $\mathrm{Y}$, Egerdie $\mathrm{B}$, Andersen $\mathrm{M}$, et al. Tamoxifen as prophylaxis for prevention of gynaecomastia and breast pain associated with bicalutamide $150 \mathrm{mg}$ monotherapy in patients with prostate cancer: a randomised, placebo-controlled, dose-response study. European urology. 2007;52(1):106-114.

43. Sun M, Cole AP, Hanna N, et al. Cognitive Impairment in Men with Prostate Cancer Treated with Androgen Deprivation Therapy: A Systematic Review and Meta-Analysis. The Journal of urology. 2018;199(6):1417-1425.

44. Nead KT, Gaskin G, Chester C, et al. Androgen Deprivation Therapy and Future Alzheimer's Disease Risk. Journal of clinical oncology : official journal of the American Society of Clinical Oncology. 2016;34(6):566-571.

45. Chung SD, Kao LT, Lin HC, Xirasagar S, Huang CC, Lee HC. Patients receiving androgen deprivation therapy for prostate cancer have an increased risk of depressive disorder. PloS one. 2017;12(3):e0173266.

46. Wu FJ, Sheu SY, Lin HC, Chung SD. Increased Fall Risk in Patients Receiving Androgen Deprivation Therapy for Prostate Cancer. Urology. 2016;95:145-150.

47. Penedo FJ, Molton I, Dahn JR, et al. A randomized clinical trial of group-based cognitivebehavioral stress management in localized prostate cancer: Development of stress management skills improves quality of life and benefit finding. Annals of Behavioral Medicine. 2006;31(3):261-270.

48. Penedo FJ, Dahn JR, Molton I, et al. Cognitive-behavioral stress management improves stressmanagement skills and quality of life in men recovering from treatment of prostate carcinoma. Cancer: Interdisciplinary International Journal of the American Cancer Society. 2004;100(1):192-200.

49. Zurth C, Sandman S, Trummel D, Seidel D, Nubbemeyer R, Gieschen H. Higher blood-brain barrier penetration of [14C]apalutamide and [14C]enzalutamide compared to [14C]darolutamide in rats using whole-body autoradiography. Journal of Clinical Oncology. 2019;37(7_suppl):156-156.

50. Gild P, Cole AP, Krasnova A, et al. Liver Disease in Men Undergoing Androgen Deprivation Therapy for Prostate Cancer. The Journal of urology. 2018;200(3):573-581. 
51. Marbury T, Lawitz E, Stonerock R, et al. Single-dose pharmacokinetic studies of abiraterone acetate in men with hepatic or renal impairment. Journal of clinical pharmacology. 2014;54(7):732-741. 


\begin{tabular}{|c|c|c|c|c|c|c|c|c|}
\hline Drug & Goserelin acetate & Leuprorelin acetate & Leuprorelin acetate & Leuprorelin acetate & Triptorelin acetate & Buserelin acetate & Degarelix acetate & Abarelix \\
\hline Brand name $^{1}$ & Zoladex $^{\circledR}$ & $\begin{array}{l}\text { Leuprorelin } \\
\text { Sandoz }^{\circledR}\end{array}$ & Lupron Depot ${ }^{\circledR}$ & Eligard $^{\circledR}$ & Decapeptyl ${ }^{\circledR}$ SR & Suprefact ${ }^{\circledR}$ & Firmagon $^{\circledR}$ & Plenaxis ${ }^{\circledR}$ \\
\hline Mode of action & LHRH-Agonist & LHRH-Agonist & LHRH-Agonist & LHRH-Agonist & LHRH-Agonist & LHRH-Agonist & LHRH-Antagonist & LHRH-Antagonist \\
\hline Preparation & Implant & Implant & Microspheres & Powder $^{2}$ & Powder ${ }^{2,3}$ & Implant & Powder $^{2}$ & Powder $^{2}$ \\
\hline Administration & s.c.: any time & s.c.: any time & s.c./i.m.: immediately & s.c.: immediately & s.c./i.m.: immediately & s.c.: any time & s.c.; within $60 \mathrm{~min}$ & i.m. \\
\hline $\begin{array}{l}\text { Flare protection } \\
\text { needed }\end{array}$ & Yes & Yes & Yes & Yes & Yes & Yes & No & No \\
\hline Dose & Always same dose & Always same dose & Always same dose & Always same dose & Always same dose & Always same dose & $\begin{array}{l}\text { First dose } 2 \times 120 \mathrm{mg} \\
\text { Regular dose } 80 \mathrm{mg}\end{array}$ & Always same dose \\
\hline Dosing frequency & 1-, or 3-monthly & 1-, or 3-monthly & 1-, 3-, 4- or 6-monthly & 1-, 3-, 4- or 6-monthly & $1-, 3-$, or 6-monthly & 2-, 3-, monthly & 1-monthly & 2-weekly \\
\hline Storage conditions & $<25^{\circ} \mathrm{c}$ & $<30^{\circ} \mathrm{C}$ & $<30^{\circ} \mathrm{C}$ & $2-8^{\circ} \mathrm{C}$ & $<25^{\circ} \mathrm{c}$ & $<25^{\circ} \mathrm{c}$ & $<25^{\circ} \mathrm{c}$ & $<25^{\circ} \mathrm{c}$ \\
\hline
\end{tabular}


Table 1 Overview of advantages and disadvantages of available LHRH Agonists and Antagonists,

${ }^{\prime}$ varies by country, ${ }^{2}$ needs Up to 15 minutes to dissolve, ${ }^{3}$ needs time to reach room temperature

Abbreviations LHRH: luteinizing hormone-releasing hormone, s.c.: subcutaneous, i.m.: intramuscular, ${ }^{\circ}$ C: Degree Celsius, G: gauge 